\title{
COCAINE USE AND STROKE
}

Paula Pire García, Mirian Rosón González, Alejandro Méndez Burgos, Carmen Martin Llorente, Laura Borrega Canelo, Manuel Barón Rubio, Laura Lillo Triguero, Francisco Javier Barriga Hernández, Maria Elena Novillo López, Pilar Sobrino García

Hospital Universitario Fundación Alcorcón, Neurology, Alcorcón, Spain

\section{INTRODUCTION}

Cocaine use among young people has become a global epidemiological issue these days.

It is an independent cerebrovascular risk factor for both ischemic and hemorragic stroke, especially among people under 55 years of age.

Stroke can be generated through a number of mechanisms: vasoespasm, vasculitis, cardioembolism (arrithmias, cardiac ischemic injury), hypertensive surges, enhanced platelet aggregation and altered cerebral autorregulation.

Our aim is to review the epidemiological characteristics, clinical profiles, prognosis and morbimortality in a cohort of cocaine-related stroke.

\section{METHODS}

We performed a retrospective analysis of patients who were admitted to the stroke unit with acute ischemic stroke and positive cocaine urine screening on admission in a period of time from January 2015 to December 2017.

\section{RESULTS}

We analyze 10 patients with acute stroke ( 9 ischemic, 1 subarachnoid hemorrhage) and positive cocaine.

- $100 \%$ male

-Median age 38.5

- Median NIHSS on admission $(2,1)$

- Low rate of neurological

complications.

-100\% had good outcome at 3

months.

\section{- Only $30 \%$ admitted cocaine use} before the results of the urine analysis were reported.

Cocaine use
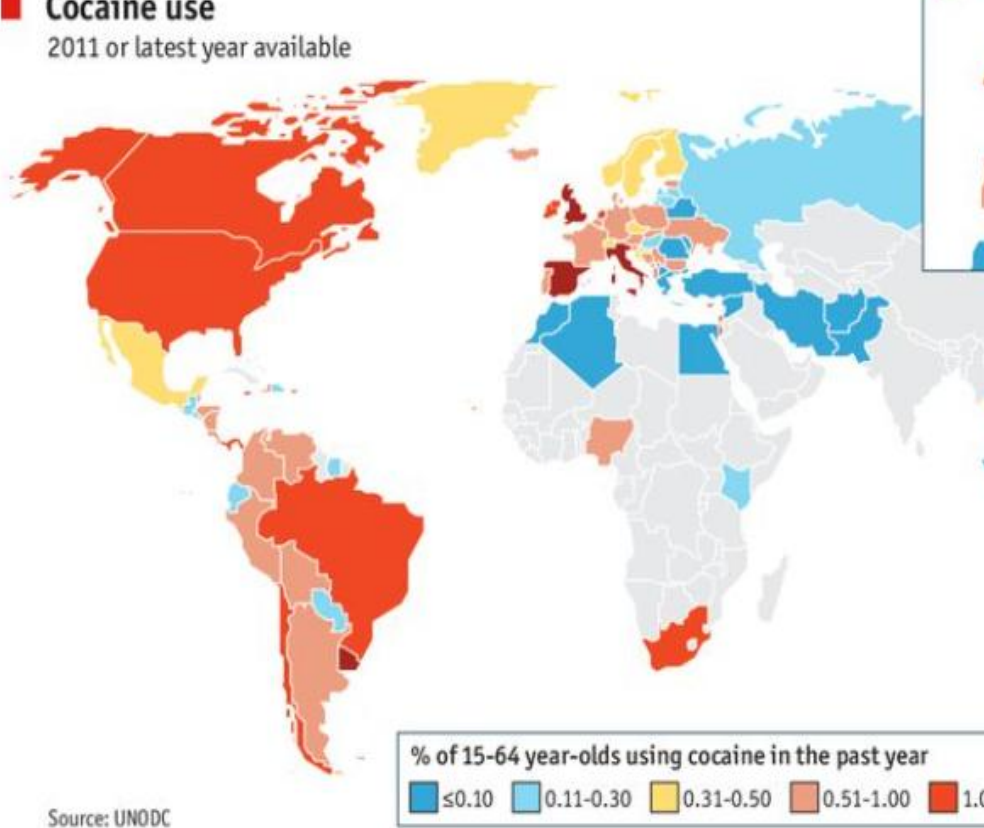

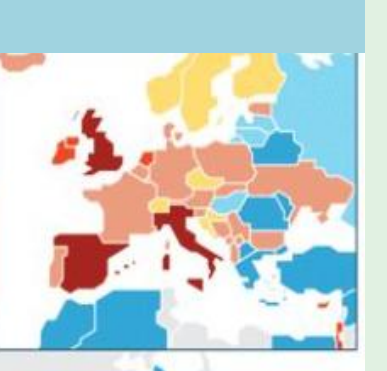

1)

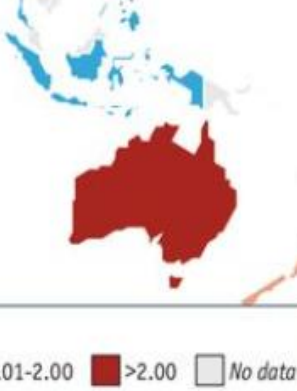

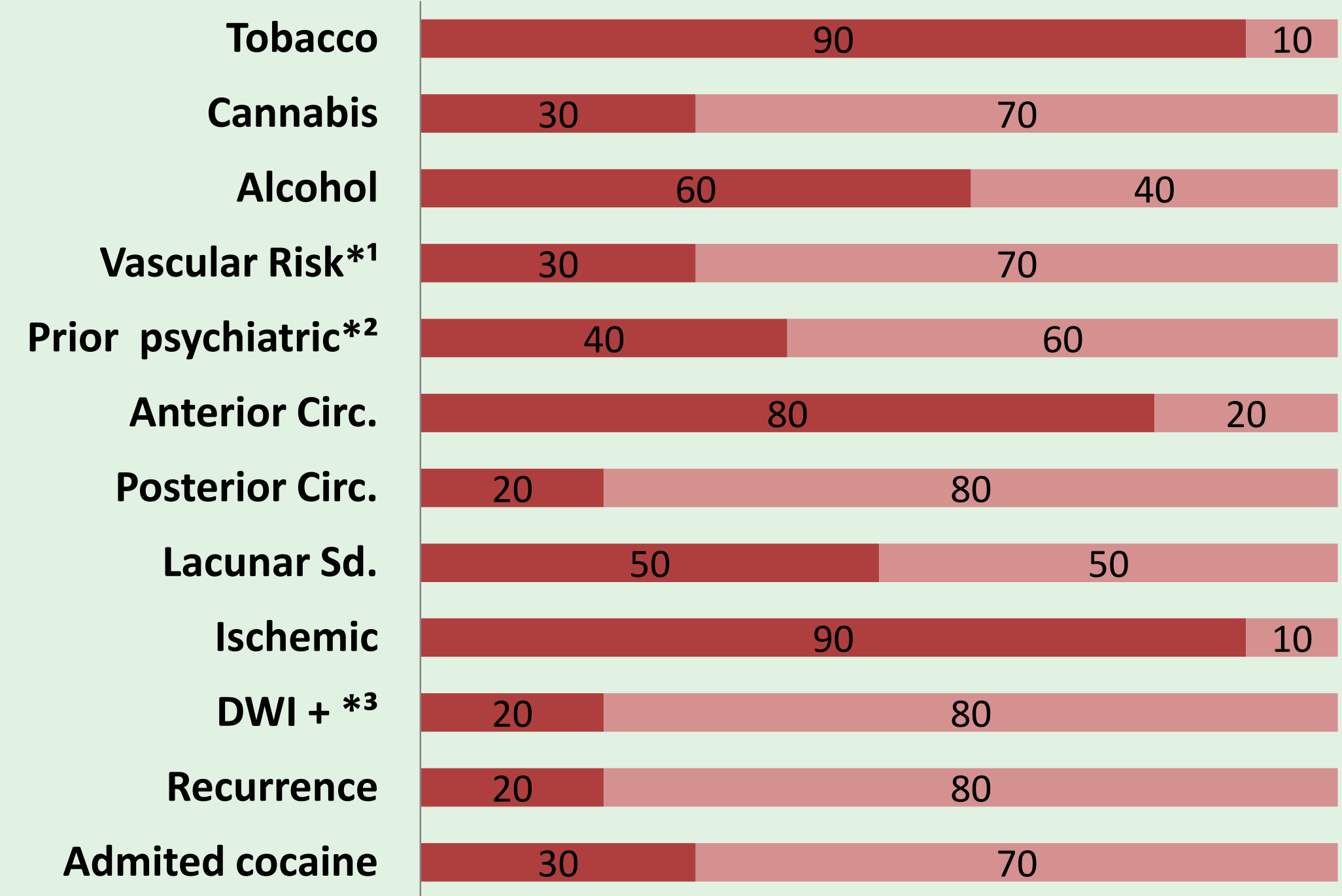

\footnotetext{
*1: Other Vascular Risk Factors as : Hypertension, Diabetes or Cholesterol.

*2: Prior Psychiatric history as anxiety or sustance abuse disorder.

*3: Established infarction in MRI
}

\section{CONCLUSIONS}

Data on cocaine use in European countries continues to show a high prevalence. Spain is one of the highest. However, there are no recent large epidemiological studies that investigate cocaine-stroke in Europe. In our study, a low morbidity and mortality were observed in comparison to previous studies. It is essential to carefully evaluate the prognosis of this group of patients; they are exposed to a potential situation of dependence very early. Cocaine should always be considered as a possible cause of stroke in young patients, even if the patient denies its use.

\section{BIBLIOGRAPHY}

1. Bhattacharya P. Clinical profiles, complications, and disability in cocaine-related ischemic stroke. J Stroke Cerebrovasc Dis Elsevier Ltd; 2011;20(5):443-9

2. Treadwell SD, Robinson TG. Cocaine use and stroke. Postgrad Med J. 2007;83(980):389-94. 